\title{
GENETIC INFLUENCES ON SARCOIDOSIS
}

\author{
MAMI ISHIHARA and SHIGEAKI OHNO \\ Kanagawa, Japan
}

\begin{abstract}
SUMMARY
To investigate the genetic influences underlying the development of sarcoidosis, HLA class II genotyping was performed in Japanese patients with sarcoidosis and healthy controls using the PCR-RFLP method. The frequencies of both DR52 group antigen-associated alleles (HLA-DRB1*11, -DRB1*12 and -DRB1*14) and DRB1*08 alleles were higher in the patient group, suggesting that the common, specific amino acid residue on the DRB1 molecule of these alleles may determine susceptibility to sarcoidosis. Alternatively, it is possible that another susceptibility gene, linked to these DRB1 alleles, exists within the MHC region. We screened the TNFA, TNFB, HSP70-1 and Hum70t genes around the class III region, as well as the HLA-DMA and -DMB genes in the class II region, for genetic polymorphism in sarcoidosis. None of these genes suggested a susceptibility to sarcoidosis. These studies support the thesis that one of the major genetic factors controlling the development of sarcoidosis is located within the DRB1 locus in the HLA class II region.
\end{abstract}

Sarcoidosis is a multisystemic granulomatous disorder characterised by an accumulation of activated $\mathrm{CD}^{+} \mathrm{T}$ cells and alveolar macrophages, which have been known to play an important role in the pathogenesis of granuloma formation. ${ }^{1}$ Although the aetiology of the disease remains unclear, infectious and environmental factors based on immunogenetic factors have been postulated. One of the genetic factors of the disease has been determined through analysis of major histocompatibility complex (MHC) genes, especially human leucocyte antigens (HLA).

The MHC region, where the genetic loci controlling susceptibility to many diseases have been mapped, is located on the short arm of chromosome $6 .^{2}$ The human MHC is a human HLA complex with a high level genetic polymorphism which regulates

Correspondence to: Shigeaki Ohno, MD, Department of Ophthalmology, Yokohama City University, School of Medicine, 3-9 Fukuura, Kanazawa-ku, Yokohama-shi, Kanagawa 236, Japan. immune response through a self/non-self discrimination mechanism. Recent advances in polymerase chain reaction (PCR)-based DNA typing techniques have made it possible to detect HLA allelic polymorphisms at the molecular level. Certain HLA genes have been found to be related to the risk of developing certain diseases. The purpose of the present study is to characterise the immunogenetic mechanisms in the pathogenesis of the development of sarcoidosis from the viewpoint of the role of HLA and non-HLA genes.

\section{HLA ASSOCIATION WITH SARCOIDOSIS}

Sarcoidosis has been shown to be associated with HLA-B8-DR $3{ }^{3,4}-\mathrm{DR} 5^{5}$ and -DR6 ${ }^{6}$ haplotypes in Caucasians. In Japanese, the association between HLA-DR52 and sarcoidosis has been confirmed several times. ${ }^{7.8}$ These previous studies were performed by conventional serological typing using the lymphocytotoxicity method. To determine the association between HLA class II alleles and sarcoidosis, we performed PCR-based genotyping for HLADRB1, -DRB3, -DQA1, -DQB1 and -DPB1 alleles in Japanese patients with histopathologically confirmed sarcoidosis.

The HLA region can be subdivided into the class I and class II gene region. HLA-DP, -DQ and -DR gene subregions have been identified in the class II region from the centromere to the telomere. HLADNA, HLA-DM, LMP, TAP and HLA-DOB genes have also been located between the DP and subregions (Fig. 1). The class II antigens, HLADR, -DQ and -DP antigens, are encoded by two genes, one encoding the $\alpha$ chain (A) and the other the $\beta$ chain (B). HLA-DR is polymorphic only for the $\beta$ chain which is encoded by the DRB1 gene, whereas HLA-DQ is polymorphic for both the $\alpha$ chain (encoded by the DQA1 gene) chain and the $\beta$ chain (encoded by the DQB1 gene). Different HLADR haplotypes have different numbers and compositions of HLA-DR genes. ${ }^{9}$ The HLA-DR region includes the common DRA and DRB1, and may have some or no DRB2, DRB3, DRB4, DBR5, 


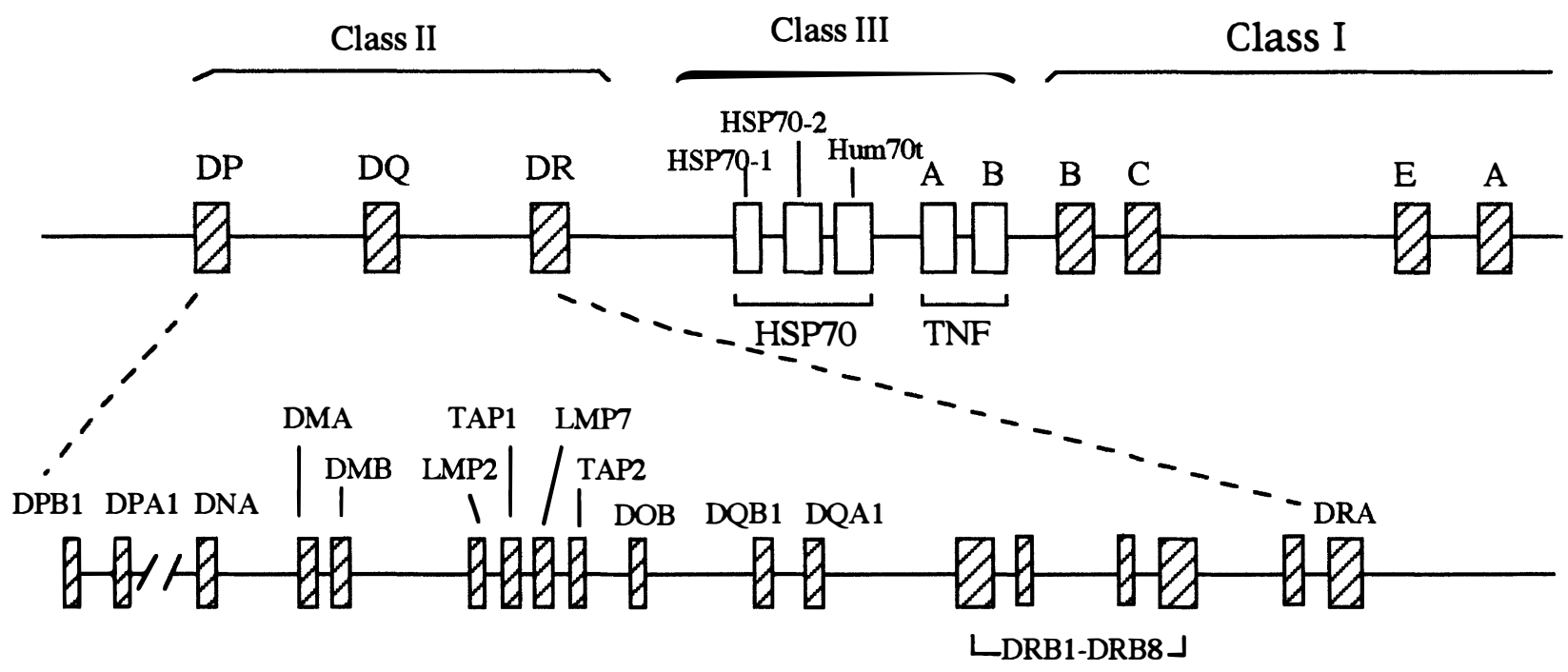

Fig. 1. Map of the $M H C$ region.

DRB6, DRB7, DRB8 or DRB9 genes, depending on the DR haplotype (Fig. 2). Of these, DRB1, DRB3, DRB4 and DRB5 are polymorphic and the rest are pseudogenes. The DRB3 gene encodes the DR52 $\beta$ chain to specify the DR52 group. The DR3 (R17 and DR18), DR5 (DR11 and DR12) and DR6 (DR13 and DR14) antigens are in complete correlation with the genetic composition of DR52. The DR52 group haplotypes (DR3, DR5 and DR6) include the DRA, DRB1 and DRB3 genes as well as two pseudogenes. The DRB1 gene is highly polymorphic and determines the DR3, DR5 and DR6 specificities. Although when serological typing was the only available method it was thought that DR8 also correlated with DR52, the DR8 group haplotype includes DRA and DRB1 genes, which determine DR8 specificity, but does not possess the DRB3 gene. On the other hand, the DR4, DR7 and DR9 antigens correlate completely with DR53. The DR53
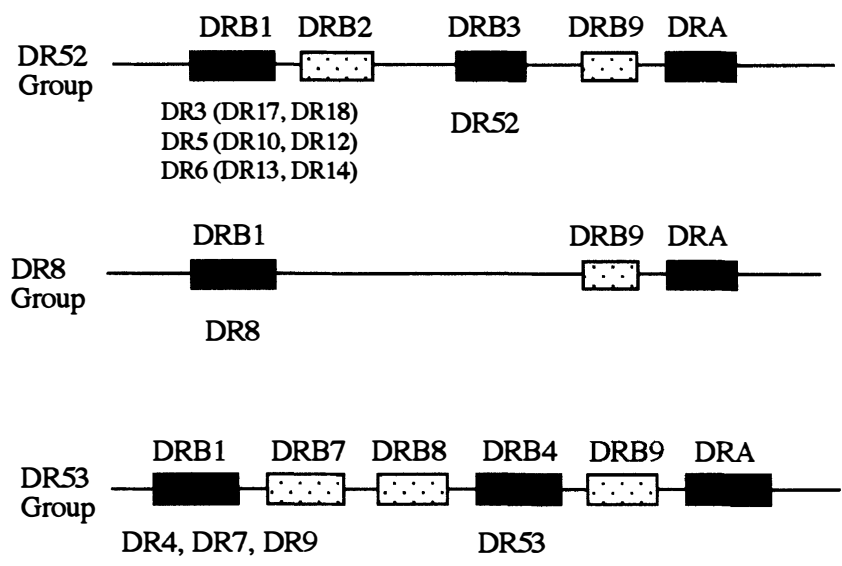

Fig. 2. Gene structure of $H L A-D R$ region with the haplotypes of the DR52, DR8 and DR53 group antigens. Black bars, expressed gene; stippled bars, pseudogene. group haplotypes (DR4, DR7 and DR9) include the DRA, DRB1 and DRB4 genes in addition to three pseudogenes. The DRB1 gene determines DR4. DR7 and DR9 specificities, while the DRB gene encodes the DR53 $\beta$ chain to specify the DR53 group.

HLA class II (HLA-DRB1, -DRB3, -DQA1, -DQB1 and -DPB1) genotyping was performed by the PCR-restriction fragment length polymorphism (RFLP) method. $^{10,11}$ Genomic DNA from 63 patients with sarcoidosis and 110 healthy controls was first extracted and purified from peripheral blood cells by the proteinase $\mathrm{K}$-phenol extraction method. ${ }^{12}$ The genomic DNA was then amplified by the PCR procedure, and the PCR product was digested with allele-specific restriction endonucleases as previously described. ${ }^{13}$

HLA-DRB1 genotyping showed that the frequencies of HLA-DRB1*11 (DRB1*1101-1105), -*12 (DRB1*1201 and 1202), -*14 (DRB1*1401-1410) and $-* 08$ (DRB1*0801-0805) were significantly higher in the patients than in the healthy controls. ${ }^{11}$ These results are consistent with the increased frequencies of HLA-DR5 (DR11 and DR12), -DR6 (DR13 and DR14) and -DR8 antigens in patients with sarcoidosis revealed by serological typing. ${ }^{10}$ Among the antigens, the frequency of DRB1*1302 (DRB1*13) was lower in the patients than in the healthy controls. Among DR52 group antigens HLA-DR3 is very rare in Japanese, although very common in Caucasians. HLA-DRB3 genotyping showed that the frequency of $\mathrm{DRB} 3 * 0101$ was significantly higher in the patient group than in the control group. However, this may represent a linkage disequilibrium with DR5- and DR6-associated DRB1 alleles. ${ }^{11.14}$ On the basis of these genotyping 
results, the DRB1 gene of HLA-DR5, -DR6 and -DR8 antigens may be primarily responsible for susceptibility to sarcoidosis. Since the frequency of DRB1*08 (DR8), which does not contain the DRB3 gene, ${ }^{9}$ was significantly higher in the patients, the DRB3 gene cannot be the susceptibility gene to sarcoidosis. In HLA-DQA1 and -DQB1 genotyping, a strong association of DQA $1 * 0501$ and DQB $1 * 0301$ with sarcoidosis was observed which can be explained by linkage disequilibrium with DR5associated alleles.11 The frequency of the DRB1*0101-DQB1*0501 -DPB1*0402 haplotype, common among Japanese, was significantly lower in the patients compared with the healthy controls. ${ }^{10.11}$ These results taken together show that HLA alleles responsible for susceptibility to sarcoidosis may be located in the DRB1 locus, rather than the DRB3, DQA1, DQB1 or DPB1 locus.

To consider the pathogenesis of the development of sarcoidosis at molecular level, amino acid sequences of DRB1 alleles were compared with each other. Amino acid residues at positions 10 to 12 were found to be common only in HLA-DR3, -DR5, -DR6 and -DR8 associated DRB1 alleles. ${ }^{15}$ Recent studies of HLA-DR $1^{16,17}$ and -DR $3^{18}$ molecules by $\mathrm{X}$-ray crystallography enabled us to find several 'pockets' in the HLA groove, to which amino acids of an antigenic peptide directly bind. Among these amino acid residues, position 11 is known to constitute a part of pocket 6 in the HLA groove ${ }^{17.18}$ and to be the position for directly binding to the amino acid of an antigenic peptide. ${ }^{19}$ Therefore, serine at position 11 in the DRB1 molecule of HLADR3, -DR5, -DR6 and -DR8 (called the DR3, 5, 6, 8 group antigens) may be responsible for the pathogenesis of sarcoidosis. ${ }^{10,11,14}$ Despite the presence of Ser-11, DRB1*1302 was the only allele of the DR3, $5,6,8$ group antigens to appear at a lower frequency in the patients than in the healthy controls. It has been postulated that the amino acid residue (glutamic acid) at position 71 , which is unique to DRB1*1302, affects the binding of helper $\mathrm{T}$ cell receptor. ${ }^{19}$ Glutamic acid at position 71 may play a protective role against the development of sarcoidosis. ${ }^{11}$ This hypothesis explains why HLA-DR3 is found to be associated with sarcoidosis in Caucasian populations. ${ }^{3,4}$

Our results on HLA class II genotyping suggest that the HLA-DRB1 gene of the DR3, 5, 6, 8 group antigens can be assumed to be the most probable candidate for determining genetic susceptibility to sarcoidosis. The question then is why individuals without DR3, 5, 6, 8 group antigens also develop the disease. It is interesting that all the patients who did not have DR3, 5, 6, 8 group antigens had HLADR53 antigen. ${ }^{10}$ HLA-DRB4 genotyping is being conducted in such patients with sarcoidosis to investigate the involvement of the DRB4 gene which encodes the DR53 $\beta$ chain to specify the DR53 group antigens (DR4, DR7 and DR9). ${ }^{9}$ In fact there is a molecular basis for some of the clinical heterogeneity observed in sarcoidosis patients with and without the DR3, 5, 6, 8 group antigens. ${ }^{14}$

\section{THE TUMOUR NECROSIS FACTOR (TNF) GENE IN SARCOIDOSIS}

Another possible explanation for the association between the HLA-DR3, 5, 6, 8 group antigens and sarcoidosis is that these antigens are a genetic marker, and that the primary or additional susceptibility gene to sarcoidosis exists within or in a linkage with the HLA region. Between the class I and class II region of the HLA is a region carrying non-HLA genes, including those encoding the complements, the adrenal enzyme steroid 21-hydroxylase, tumour necrosis factor (TNF)- $\alpha$ and TNF- $\beta$ and three members of the heat shock protein (HSP)70 family (Fig. 1). Some of these may also play an important role in the immune response. The genes for TNF- $\alpha$ and TNF- $\beta$ are in the class III region, 250 kilobases $(\mathrm{kb})$ centromeric to the HLA-B locus. ${ }^{20}$

TNF- $\alpha$ and $-\beta$ are cytokines, potent immunomodulators ${ }^{21}$ which play an important role in the association between HLA autoimmune diseases. ${ }^{22-24}$ The level of TNF- $\alpha$ protein production is known to be higher in the bronchoalveolar lymphoid fluid of patients with sarcoidosis than in healthy individuals. $^{25}$ TNF- $\alpha$ is produced by macrophages, ${ }^{26}$ and promotes granuloma formation. Variations in TNF- $\alpha$ production rates between individuals have been demonstrated to correlate with some HLA-DR haplotypes in Caucasians ${ }^{27,28}$ and with polymorphic sequences closely linked to the TNFB locus: namely, the NcoI diallelic RFLP in the first intron of the TNFB gene (TNFB*). ${ }^{29}$ First, we analysed TNFB diallelic polymorphism in 75 patients with sarcoidosis and 75 healthy controls, using the PCR-RFLP method. ${ }^{30}$ Polymorphism at position 252 in the first intron results in an amino acid substitution at amino acid position $26 .{ }^{29}$ To detect an NcoI diallelic RFLP of the TNFB gene (TNFB*1 and TNFB*2), the 368 base pair (bp) fragment in the first intron was amplified by the PCR procedure. TNFB* 1 has an NcoI restriction site $(235 \mathrm{pb}$ and $133 \mathrm{bp}$ cleaved fragments), whereas $\mathrm{TNFB}^{* 2}$ does not. The allele frequency of TNFB*1 was significantly increased in the patients with sarcoidosis as compared with the healthy controls. ${ }^{30}$ However, the increased frequency of TNFB*1 may be explained by linkage disequilibrium with HLA-DR5, -DR6 and -DR8 linked HLA$\mathrm{B}$ alleles, which are known to be linked strongly with TNFB alleles. ${ }^{31}$ 


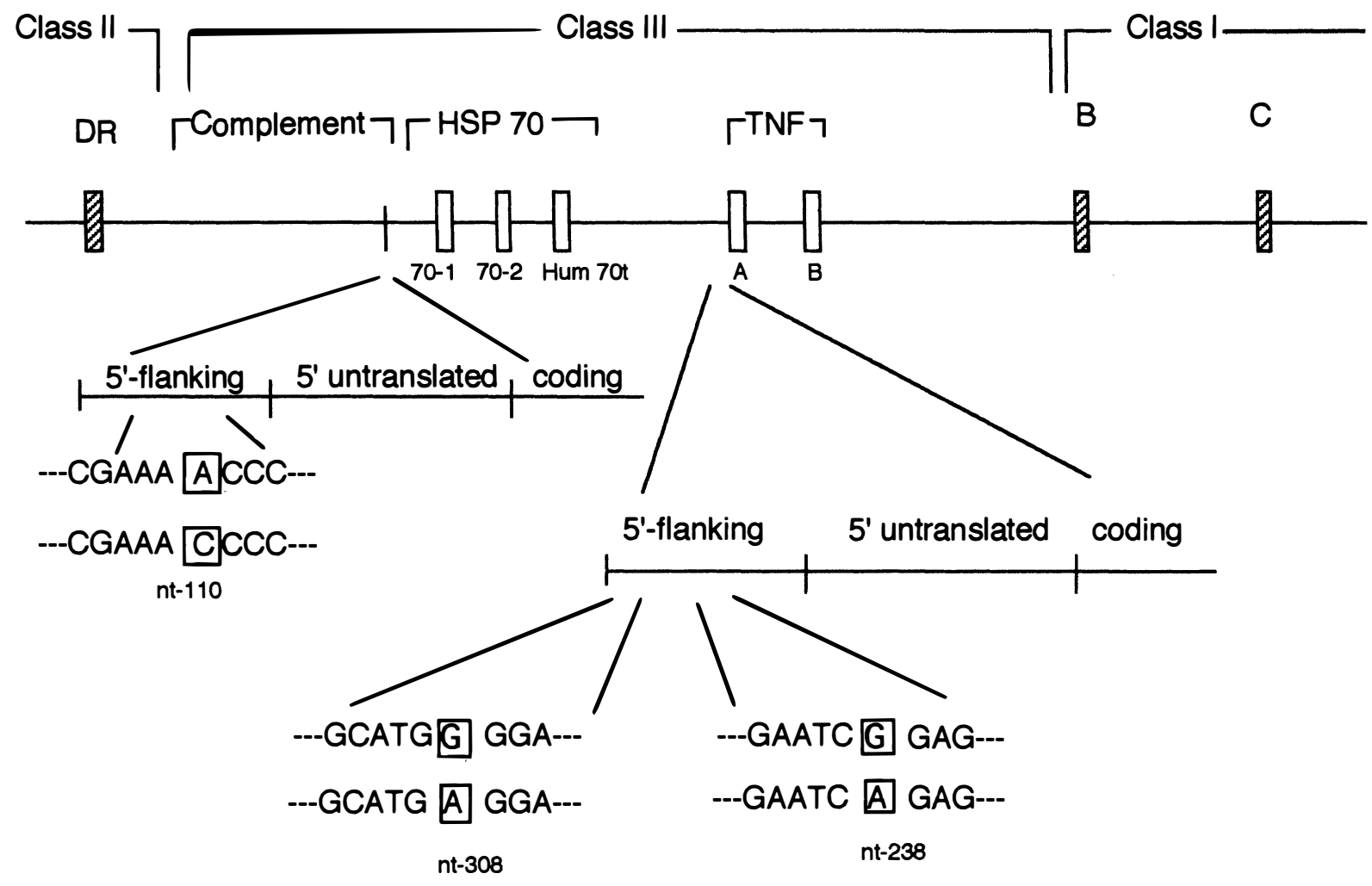

Fig. 3. Polymorphisms in the 5'-flanking region of the TNFA and HSP70-1 genes. $G-A$ substitution at position -308 and $G$-A substitution at position -238 were identified in the TNFA gene, and A-C substitution at position-110 was identified in the HSP70-1 gene.

The 5'-flanking (promoter-enhancer) region of the TNFA gene is involved in transcriptional regulation of TNFA expression. ${ }^{32}$ Recently, diallelic polymorphisms have been identified in the promoterenhancer region of the TNFA gene (TNFA*): namely, A-G substitution at position $-308^{33}$ and G-A substitution at position $-238^{34}$ (Fig. 3). We analysed these two polymorphic sites of the TNFA gene in 67 patients with sarcoidosis and 64 healthy controls using the PCR-RFLP method.

The TNFA region incorporating these two polymorphic sites was amplified by the PCR method using the following primers: 5'-AGGCAATAGGTTTTGAGGGCCAT-3' and 5'-ACACTCCCCATCCTCCCGGCT- $3^{\prime} .{ }^{35}$ The diallelic polymorphism at position -308 was detected by $N$ coI digestion of the amplified 117 bp product. TNFA$308 *$ A yielded two fragments of $97 \mathrm{bp}$ and $20 \mathrm{bp}$, whereas TNFA-308*G had no NcoI site. TNFA238 alleles were detected by NlaIV digestion of the

Table I. Phenotype frequencies of the TNFA gene in the patients with sarcoidosis and the healthy controls

\begin{tabular}{lcc}
\hline TNFA allele & $\begin{array}{c}\text { Patients } \\
(n=67)\end{array}$ & $\begin{array}{c}\text { Controls } \\
(n=64)\end{array}$ \\
\hline TNFA-308*A & $67(100 \%)$ & $64(100 \%)$ \\
TNFA-308*G & $2(2.9 \%)$ & $2(3.1 \%)$ \\
TNFA-238*G & $67(100 \%)$ & $64(100 \%)$ \\
TNFA-238*A & 0 & 0 \\
\hline
\end{tabular}

PCR-amplified 117 bp product. TNFA-238*A showed two fragments of $70 \mathrm{bp}$ and $47 \mathrm{bp}$, while TNFA- $238 * \mathrm{G}$ had three fragments of $50 \mathrm{bp}, 47 \mathrm{bp}$ and $20 \mathrm{bp}$.

As shown in Table I, our analysis of genetic polymorphism in the TNFA gene of healthy Japanese controls and those with sarcoidosis indicated a rather low degree of polymorphism in this gene. There were no differences observed in the phenotype frequency of these TNFA alleles between the patients and the healthy controls.

It has been reported that TNFB* 1 homozygous individuals show an elevated level of TNF- $\alpha$ production relative to $\mathrm{TNFB}^{* 2}$ homozygous individuals upon phytohaemagglutinin stimulation of peripheral blood mononuclear cells. ${ }^{29}$ Although some degree of association has been observed between the TNFB*1 allele and sarcoidosis, this may be attributed to linkage disequilibrium between TNFB and HLA genes. Furthermore, Jacob et al. ${ }^{27}$ demonstrated that HLA-DR3 and -DR4 positive subjects produced high levels of TNF- $\alpha$, while Wilson et al. ${ }^{28}$ reported that $\mathrm{A}$ at position -308 (TNFA- $308^{*} \mathrm{~A}$ ) was strongly associated with the HLA-DR3 haplotype. We suggest that TNFA-308*A allele may be a high TNF- $\alpha$ producer.

On the other hand, TNFA-238*A allele has been reported to be associated with HLA-DR17 (a subtype of DR3) and -DR7 haplotypes. ${ }^{34}$ Taken 
together, TNFB*1, TNFA-308*A and TNFA-238*A alleles may be high producers of $\mathrm{TNF}-\alpha$ and associated with HLA-DR3 haplotypes. Since HLADR3 is one of the major antigens in Caucasians and closely associated with Caucasian patients with sarcoidosis, ${ }^{3,4}$ it is possible that the TNFA or TNFB gene is the susceptibility gene to the development of sarcoidosis in Caucasians. However, in Japanese, DR3 is a very rare antigen and no TNFA or TNFB allele could reflect the production of TNF$\alpha$ in sarcoidosis. With regard to the high level of TNF- $\alpha$ production in patients with sarcoidosis, there is a possibility that other regulatory mechanisms such as post-transcriptional regulation may play a role in the pathogenesis of sarcoidosis. Alternatively, there could be disease-specific regulation of TNFA or TNFB gene expression different from the one for healthy individuals.

\section{HEAT SHOCK PROTEIN (HSP) 70 GENES IN SARCOIDOSIS}

The $70 \mathrm{kDa}$ heat shock proteins (HSP70) are known to be major antigens in many bacterial and parasitic infections and to be involved in antigen processing and presentation. ${ }^{36}$ The high degree of sequence homology between endogenous HSPs and bacterial HSPs may cause antibodies or $\mathrm{T}$ cells directed against the bacterial HSPs also to attack their own HSPs, leading to autoimmune diseases. Three genes encoding members of the HSP70 family are also located in the class III region of HLA, between the complement and TNF genes, $92 \mathrm{~kb}$ telomeric of the C2 gene. ${ }^{37}$ They are named HSP70-1, HSP70-2 and Hum70t (HSP70-Hom). ${ }^{38}$ The HSP70-1 and HSP702 genes are expressed at high levels after thermal shock. The Hum70t gene, located $4 \mathrm{~kb}$ telomeric of the HSP70-1 gene, is expressed specifically in spermatids. The existence of anti-HSP70 antibodies in the peripheral blood of patients with sarcoidosis (M. Asano et al., unpublished data) suggests that HSP70 may control the predisposition to sarcoidosis.

Recently, limited polymorphisms in these three (HSP70-1, HSP70-2 and Hum70t) genes have been identified and characterised ${ }^{39}$ In the HSP70-1 gene, three polymorphic sites were found in the $5^{\prime}$ flanking, $5^{\prime}$ untranslated $\left(5^{\prime} \mathrm{UT}\right)$ regions and in the coding sequence. In the Hum70t gene, two polymorphic sites were identified in the coding sequence. To investigate the possibility that the HSP70 genes may play a role in the pathogenesis of sarcoidosis, we analysed genetic polymorphisms in the $5^{\prime}$-flanking region (designated as HSP70-1*a) and the 5' UT (designated as HSP70-1*b) of the HSP70-1 gene and the coding region of the Hum70t gene (designated as Hum 70t*b) in both the patients with sarcoidosis and the healthy controls.
In our previous report, we investigated the polymorphisms in the $5^{\prime} \mathrm{UT}$ region of the HSP70-1 gene and in the coding region of the Hum70t gene by the PCR-RFLP method in 53 patients with sarcoidosis and 50 healthy controls. ${ }^{30}$ The polymorphism at position 190 in the 5' UT region of the HSP70-1 gene was determined using NlaIV digestion of the PCR product. The polymorphism at position 2347 in the coding region of the Hum70t gene, which causes an amino acid substitution from methionine to threonine, was detected using $N c o$ I digestion of the amplified product. There was no difference in allele frequency of the HSP70 $1 * b$ or Hum $70 t * b$ gene observed between the patient and control groups.

Furthermore, the polymorphism at position -110 in the 5'-flanking region of the HSP70-1 gene (Fig. 3) was identified by single-strand conformation polymorphism (SSCP) analysis after PCR amplification was performed in 54 patients with sarcoidosis and 47 healthy controls. Genomic DNA was amplified for SSCP analysis by PCR using the following primers: 5'-CGCCATGGAGACCAACACC-3' and 5'-AAAGGTAGTGGTCTGTCGCAGCA-3'.

Amplification was performed for 30 cycles, with 1 minute incubation for each step at 96,56 and $72^{\circ} \mathrm{C}$, respectively. PCR products $(3 \mu \mathrm{l})$ were mixed with $4.9 \mu \mathrm{l}$ of a solution containing $80 \%$ formamide, 20 $\mathrm{mM}$ EDTA and $0.01 \%$ bromphenol blue. The mixture was then incubated at $95^{\circ} \mathrm{C}$ for 5 minutes and chilled on ice. Samples $(3 \mu \mathrm{l})$ were subjected to electrophoresis on $10-20 \%$ polyacrylamide gradient gels for 3-4 hours at $4{ }^{\circ} \mathrm{C}$ and a constant current of $20 \mathrm{~mA}$. Gels were stained with a silver stain kit (Daiichi Chemical Co., Tokyo, Japan). DNA fragments showing altered electrophoretic mobility by SSCP were reamplified by PCR, and the purified PCR products were then sequenced by dideoxychain termination with a DNA sequencer (model 373A, Applied Biosystems).

Sequence analysis resulted in the identification of the HSP70-1*a1 allele, which contains A at position -110 , and the HSP70-1*a2 allele, which contains $\mathrm{C}$ at the same position. As shown in Table II, no significant difference in the allelic distribution of the polymorphism at position -110 in the $5^{\prime}$-flanking region of the HSP70-1 gene was observed between the patient and control groups.

The HSP70-1 gene may be regulated by the interaction of the heat shock transcription factor (HSF) with the heat shock element (HSE) present in

Table II. Allele frequencies of the $5^{\prime}$-flanking region in the HSP70-1 gene in the patients with sarcoidosis and the healthy controls

\begin{tabular}{lccc}
\hline Allele & $\begin{array}{c}\text { Nucleotide } \\
\text { position }-110\end{array}$ & $\begin{array}{c}\text { Patients } \\
(n=54)\end{array}$ & $\begin{array}{c}\text { Controls } \\
(n=47)\end{array}$ \\
\hline HSP70-1*a1 & A & $64(59.3 \%)$ & $54(57.4 \%)$ \\
HSP70-1*a2 & C & $44(40.7 \%)$ & $40(42.6 \%)$ \\
\hline
\end{tabular}


its $5^{\prime}$-flanking region. ${ }^{40}$ Heat shock treatment induces the rapid binding of HSF to the promoter of HSP701 , which alters the pattern of methylation reactivity of the region encompassing the NGAAN site of HSEs. The polymorphic site is assumed to include the HSEs, suggesting that the polymorphism of the 5 '-flanking region in the HSP70-1 gene may affect both gene expression and protein production. The polymorphism at position -110 in the HSP70-1 gene has been demonstrated to be associated with HLADR alleles in Caucasians: a $\mathrm{C}$ at position -110 (HSP70-1*a2) is associated with HLA-DR3. ${ }^{41}$ Therefore, this polymorphism may contribute to the development of DR3-associated autoimmune diseases in Caucasians, including sarcoidosis. However, our results exclude HSP70 gene polymorphism as a genetic factor in the development of sarcoidosis.

\section{HLA-DM GENE IN SARCOIDOSIS}

The HLA-DMA and -DMB genes, recently identified between the HLA-DQ and -DP genes within the HLA, encode a novel human MHC class II molecule. ${ }^{42}$ Although the function of the DM gene is not completely understood, the DM molecule may be directly involved in the class II-dependent peptide presentation pathway in the immune response requiring the removal of the invariant chain peptide. ${ }^{43}$ Genetic polymorphisms, mainly in the third exons of both the DMA and DMB genes, have been reported. The DMA gene has four alleles (HLADMA*0101-0104) $)^{44}$ and the DMB gene has five (HLA-DMB*0101-0105). ${ }^{44,45}$

To better understand the molecular basis of the association between the class II component and sarcoidosis, we evaluated whether or not the polymorphism of the DM gene is a predisposing genetic factor for sarcoidosis. The alleles of the DMA and DMB genes were identified in 70 patients with sarcoidosis and 95 healthy controls using the PCRRFLP method. ${ }^{46}$ The PCR-amplified products were digested with ApeLI, HinplI and BsrI for DMB, and HinfI, FokI, SfanI and AciI for DMA.

No significant differences in the frequency of the DMA alleles were observed between patients and the healthy controls. On the other hand, the frequency of $\mathrm{DMB}^{*} 0102$ was significantly higher and that of $\mathrm{DMB}^{*} 0101$ was significantly lower in the patients than in the healthy controls. ${ }^{46}$ Since linkage disequilibria between HLA-genes and HLA class II genes were observed, the increased frequency of $\mathrm{DMB}^{*} 0102$ in the patients is attributed to the weak linkage disequilibrium with DRB $1 * 1101$, the allele that was significantly increased in the patients with sarcoidosis. ${ }^{11}$ The decreased frequency of DMB*0101 in the patients can be explained by its linkage disequilibria with DRB1*0101 and DPB $1 * 0402$, which were lower in the patients with sarcoidosis. ${ }^{11}$ Therefore, HLA-DMA and -DMB genes are not directly involved in the development of sarcoidosis. The DM genes are believed to have diverged at about the time that class I and class II sequences split from each other, and represent primordial MHC genes. ${ }^{47}$ Furthermore, concerning their limited polymorphism as compared with those in other HLA class I or class II genes, ${ }^{44}$ it is not very likely that HLA-DM genes are directly involved in susceptibility to the disease.

\section{CONCLUSION}

In the course of these studies we have found that the HLA-DRB1 gene may be directly involved in the pathogenesis of the development of sarcoidosis. The pathogenesis underlying sarcoidosis can be discussed in the context of amino acid residues at specific positions on the HLA-DRB1 molecule. However, it does not completely negate the association with sarcoidosis of other non-HLA genes located near the HLA-DRB1 gene. Intensive analysis of genetic polymorphism specific to sarcoidosis in these known genes is necessary for the further study of sarcoidosis.

Key words: Sarcoidosis, Disease susceptibility, Human leukocyte antigen (HLA), Tumour necrosis factor (TNF), Heat shock protein 70 (HSP70), HLA-DM.

\section{REFERENCES}

1. Thomas PD, Hunninghake GW. Current concept of the pathogenesis of sarcoidosis. Am Rev Respir Dis 1987;135:747-60.

2. Lawrance SK, Smith CL, Srivastava R, et al. Megabasescale mapping of the HLA gene complex by pulsed field gel electrophoresis. Science 1987;235: 1387-90.

3. Hedfors EVA, Lindstorni F. HLA-B8/DR3 in sarcoidosis. Tissue Antigens 1983;22:200-3.

4. Martinetti M, Tinelli C, Kolek V, et al. The Sarcoidosis Map: A joint survey of clinical and immunogenetic findings in two European countries. Am J Respir Crit Care Med 1995;152:557-64.

5. Nowack D, Goebel KM. Genetic aspects of sarcoidosis: class II histocompatibility antigens and a family study. Arch Intern Med 1987;147:481-3.

6. Odum N, Milman N, Jakobsen BK, et al. HLA class II (DR, DQ, DP) in patients with sarcoidosis: evidence of an increased frequency of DR6. Exp Clin Immunogenet 1991;8:227-32.

7. Kunikane H, Abe S, Tsuneta Y, et al. Role of HLADR antigens in Japanese patients with sarcoidosis. Am Rev Respir Dis 1987;135:688-91.

8. Abe S, Yamaguchi E, Makimura S, et al. Association of HLA-DR with sarcoidosis: correlation with clinical course. Chest 1987;92:488-90.

9. Bodmer JG, Marsh SCE, Albert ED, et al. Nomenclature for factors of the HLA system, 1991. Tissue Antigens 1992;39:161-73.

10. Ishihara $\mathrm{M}$, Ohno $\mathrm{S}$, Ishida $\mathrm{T}$, et al. Analysis of susceptibility genes in sarcoidosis. J Jpn Ophthalmol Soc 1994;98:80-5.

11. Ishihara M, Ohno S, Ishida T. Molecular genetic 
studies of HLA class II alleles in sarcoidosis. Tissue Antigens 1994;43:238-41.

12. Inoko H, Ando A, Ito M, Tsuji K. Southern hybridisation of DNA polymorphism in the HLA-D region. Hum Immunol 1986;16:304-13.

13. Inoko H, Ota M. PCR-RFLP. In: Hui KM, Bidwell JL, editors. Handbook of HLA typing techniques 1993. Boca Raton: CRC Press, 1993:9-70.

14. Ishihara M, Ishida T, Mizuki N, et al. Clinical features of sarcoidosis in relation to HLA distribution and HLA-DRB3 genotyping by PCR-RFLP. Br J Ophthalmol 1995;79:322-5.

15. Marsh SGE, Bodmer JG. HLA class II nucleotide sequences, 1991. Tissue Antigens 1991;37:181-9.

16. Brown JH, Jardetzky TS, Gorga JC, et al. Threedimensional structure of the human class II histocompatibility antigen HLA-DR1. Nature 1993;364:33-9.

17. Stern LJ, Brown JH, Jardetzky TS, et al. Crystal structure of the human class II MHC protein HLADR1 complexed with an influenza virus peptide. Nature 1994;368:215-21.

18. Ghosh P, Amaya M, Mellins E, Wiley DC. The structure of an intermediate in class II MHC maturation: CLIP bound to HLA-DR3. Nature 1995; 378:457-62.

19. Brown JH, Jardetzky TS, Saper MA, et al. A hypothetical model of the foreign antigen binding site of class II histocompatibility molecule. Nature 1988; 332:845-50.

20. Spies T, Blank G, Bresnaham M, et al. A new cluster of genes within the human major histocompatibility complex. Science 1989;243:214-6.

21. Beutler B, Cerami A. The biology of cachectin/TNF, a primary mediator of the host response. Annu Rev Immunol 1989;7:625-55.

22. Pociot F, Briant L, Mölvig J, et al. Association of tumor necrosis factor (TNF) and class II major histocompatibility complex alleles with the secretion of TNF- $\alpha$ and TNF- $\beta$ by human mononuclear cells: a possible link to insulin-dependent diabetes mellitus. Eur J Immunol 1993;23:224-31.

23. Kim TG, Kim HY, Lee SH, et al. Systemic lupus erythematosus with nephritis is strongly associated with the TNFB*2 homozygote in the Korean population. Hum Immunol 1996:46:10-7.

24. McGuire W, Hill AVS, Allsopp CEM, et al. Variation in the TNF- $\alpha$ promoter region associated with susceptibility to cerebral malaria. Nature 1994;371:508-11.

25. Walker C, Bauer W, Braun RK, et al. Activated T cells and cytokines in broncho-alveolar lavages from patients with various lung diseases associated with eosinophilia. Am J Respir Crit Care Med 1994;150: 1038-48.

26. Economou JS, Rhoades K, Essner R. Genetic analysis of the human tumor necrosis factor $\alpha$ cachectin promoter region in a macrophage cell line. J Exp Med 1990;170:321-6.

27. Jacob CO, Fronek Z, Lewis GD, et al. Heritable major histocompatibility complex class II-associated differences in production of tumor necrosis factor: relevance to genetic predisposition to systemic lupus erythematosus. Proc Natl Acad Sci USA 1990;87: 1233-7.

28. Wilson AG, de Vries N, Pociot F, et al. An allelic polymorphism within the human tumor necrosis factor $\alpha$ promoter region is strongly associated with HLA A1, B8 and DR3 alleles. J Exp Med 1993;177: 557-60.

29. Messer G, Spengler U, Jung MC, et al. Polymorphic structure of the human necrosis factor (TNF) locus: an NocI polymorphism in the first intron of the human TNF $\beta$ gene correlates with a variant amino acid in position 26 and a reduced level of TNF $\alpha$ production. Exp Med 1991;173:209-19.

30. Ishihara $\mathrm{M}$, Ohno $\mathrm{S}$, Ishida $\mathrm{T}$, et al. Genetic polymorphisms of the TNFB and HSP70 genes located in the human major histocompatibility complex in sarcoidosis. Tissue Antigens 1995;46:59-62.

31. Mizuki N, Inoko H, Sugimura K, et al. RFLP analysis in the TNF- $\beta$ gene and the susceptibility to alloreactive NK cells in Behçet's disease. Invest Ophthalmol Vis Sci 1992:33:3084-90.

32. Han J, Brown T, Beutler B. Endotoxin-responsive sequences control a cachectin/tumor necrosis factor biosynthesis at the translational level. J Exp Med 1990;171:465-75.

33. Wilson AG, di Giovine FS, Blakemore AIF, Duff GW. Single base polymorphism in the human tumor necrosis alpha (TNF $\alpha)$ gene detectable by $N c o$ I restriction of PCR product. Hum Mol Genet 1992;1:853.

34. D'Alfonso S, Richiardi PM. A polymorphic variation a putative regulation box of the TNFA promoter region. Immunogenetics 1994;39:150-4.

35. Galbraith GMP, Pandey JP. Tumor necrosis factor alpha (TNF- $\alpha)$ gene polymorphism in alopecia areata. Hum Genet 1995;96:433-6.

36. Pierce SK, DeNagel DC, VanBuskirk AM. A role for heat shock proteins in antigen processing and presentation. Curr Top Microbiol Immunol 1991;167:83-92.

37. Sargent CA, Durham I, Trowsdale J, Campbell RD. Human major histocompatibility complex contains genes for the major heat shock protein HSP70. Proc Natl Acad Sci USA 1989;86:1968-72.

38. Milner CM, Campbell RD. Structure and expression of the three MHC-linked HSP70 genes. Immunogenetics 1990;32:242-51.

39. Milner CM, Campbell RD. Polymorphic analysis of the three MHC-linked HSP70 genes. Immunogenetics 1992:36:357-62.

40. Abravaya K, Phillips B, Morimoto RI. Heat shockinduced interactions of heat shock transcription factors and the human hsp70 promoter examined by in vivo footprinting. Mol Cell Biol 1991;11:586-92.

41. Cascino I, Sorrentino R, Tosi R. Strong genetic association between HLA-DR3 and a polymorphic variation in the regulatory region of the HSP70-1 gene. Immunogenetics 1993;37:177-82.

42. Kelly AP, Monaco JJ, Cho S, et al. A new HLA class II-related locus, DM. Nature 1991;353:571-3.

43. Sloan VS, Cameron P, Porter G, et al Mediation by HLA-DM of dissociation of peptides from HLA-DR. Nature 1995;375:802-6.

44. Bodmer JG, Marsh SGE, Albert ED, et al. Nomenclature for factors of the HLA system, 1995. Hum Immunol 1995;43:149-64.

45. Naruse TK, Kawata $\mathrm{H}$, Ishihara M, et al. Analysis on allelic variation of the HLA-DMB gene in Japanese by PCR-RFLP as well as direct DNA sequencing and identification of a new DMB allele, DMB*0105. Tissue Antigens 1996;47:530-7.

46. Ishihara M, Naruse T, Ohno S, et al. Analysis of HLADM polymorphisms in sarcoidosis. Hum Immunol 1996;49:144-6.

47. Radlay E, Alderton RP, Kelly A, et al. Genomic organisation of HLA-DMA and HLA-DMB. J Biol Chem 1994;269:18834-8. 